\title{
CRITÉRIOS DE SELEÇÃO PARA O TRABALHO DE ADOLESCENTES-JOVENS: PERSPECTIVA DOS EMPREGADORES ${ }^{1}$
}

\author{
Sheila Gonçalves Câmara* \\ Jorge Castellá Sarriera
}

\begin{abstract}
RESUMO. Foi realizado, junto a 178 empresas de médio porte da cidade de Porto Alegre, um estudo exploratório que pesquisou critérios de seleção utilizados pelos empregadores de jovens. Elaborou-se um modelo teórico de empregabilidade. $\mathrm{O}$ instrumento foi construído após entrevistas semi-estruturadas com seis empregadores para identificar indicadores e variáveis do contexto. Foram identificadas também variáveis presentes na literatura empírica. Foram levantados dados biodemográficos, de escolaridade, características pessoais, habilidades esperadas e critérios da empresa (institucionais e legais). Os resultados obtidos configuraram o perfil de empregabilidade de jovens e identificaram as limitações para o exercício da função empregatícia. O modelo empírico obtido enfatiza o determinismo socioeconômico. Os programas de inserção de jovens para o trabalho poderão se utilizar dos resultados da pesquisa para instrumentalizar melhor os jovens candidatos. Os dados poderão servir de base para trabalhar, junto aos empregadores, suas crenças, seus valores e seus critérios de seleção de jovens.
\end{abstract}

Palavras-chave: seleção profissional, desemprego juvenil, empregabilidade.

\section{APPROACHES OF SELECTION FOR THE WORK OF YOUNG ADOLESCENTS: THE EMPLOYER'S PERSPECTIVE}

\begin{abstract}
This exploratory study with 178 medium-size enterprises of the Porto Alegre city, investigated approaches of selection used by employers of youngsters. An employability theoretical model was elaborated. The instrument was built after semi-structured interview with six employers to identify contextual indicators and variables. Variables present in the empirical literature were also identified. Data on education, personal characteristics, expected abilities and enterprises discretion (institutional and legal) and biodemographical. The obtained results shaped the youngster's employability profile and identified the restrictions to the employability function. The obtained empirical model, emphasizes the social-economic determinism. The Work Recruiting Programs for Youngsters will be able to use the research results to better prepare the young candidates. The data will serve as basis to work along with the employers their beliefs, values and discretion on the selection of youngsters.
\end{abstract}

Key words: Professional selection, youngster unemployment, employability.

\section{INTRODUÇÃO}

Configurando-se o desemprego um problema que vem afetando a economia em nível mundial, não podemos deixar de mencionar que um dos segmentos sociais que mais sofre suas conseqüências é, sem dúvida, a população jovem. Talvez, um dos principais entraves desta faixa etária que se depara frontalmente com essa dificuldade seja a falta de experiência com o trabalho.

$\mathrm{Na}$ realidade brasileira podemos pensar na existência de múltiplos fatores que intervêm como dificultadores da inserção de jovens no mercado de trabalho. Precisamos considerar a qualidade da

1 Trabalho desenvolvido no Grupo de Pesquisa em Psicologia Comunitária da PUCRS com o apoio das agências CAPES e FAPERGS.

* Psicóloga, Doutoranda e Mestre em Psicologia Social e da Personalidade pela PUCRS.

\# Psicólogo, Doutor em Psicologia Social pela Universidade Autônoma de Madri, Mestre em Psicologia Escolar pela PUCRS, Pesquisador do CNPq, Coordenador do Grupo de Pesquisa em Psicologia Comunitária da PUCRS e Professor da Faculdade de Psicologia e do Programa de Pós-Graduação em Psicologia da PUCRS.

Endereço para correspondência: Av. Protásio Alves, 7157/703, bloco 6, Porto Alegre - RS. CEP - 91310-003. Fone: (0xx51) 320-3500, Ramal 4207, Fax: (0xx51) 320-3633. E-mail: sarriera@ pucrs.br 
educação oferecida pelo sistema escolar, que muitas vezes não se encontra adequada às novas exigências de uma formação global. Por vezes a escola se situa tão à parte da realidade, ou como tão ineficiente em termos de recursos educacionais que muitos jovens, a abandonam e partem em busca de experiências mais concretas no mundo do trabalho. Acrescenta-se ainda a premência das dificuldades econômicas, aumentando a busca por ocupações mais produtivas em termos financeiros (Sarriera, 1994; Sarriera \& Verdin, 1996; Sarriera \& Teixeira, 1997).

Os indivíduos e as relações que estabelecem só podem ser realmente compreendidos com base no pressuposto de pertencimento a "um contexto social multideterminado, multiestruturado e de múltiplos níveis". Essa premissa possibilita o trânsito num campo bastante flexível, porém complexo, de situações e alternativas que configuram o desenvolvimento da pessoa (Westergaard \& Kelly, 1992, p. 38). Nesse sentido, é preciso pensar na questão emprego-desemprego sob um cenário mais amplo, no qual se verifica uma rede de relações específicas que se entrecruzam (Bronfenbrenner, 1979/1996), desde o âmbito do microssistema do indivíduo ou grupo até o do macrossistema, pressupostos que congiguram o Paradigma Ecológico.

Partindo dessas concepções, e buscando abarcar o maior número de fatores envolvidos, passamos a apresentar o modelo de empregabilidade de jovens que construímos para este estudo. Cabe, nesse sentido, expor a definição de empregabilidade que vem sendo utilizada em estudos recentes na área de emprego/desemprego.

Blanch (1990), em seu modelo, integra os aspectos situacionais e pessoais como fatores da ocupabilidade, ao passo que considera o indivíduo, com todos os seus aspectos psicossociais latentes, como o fator primordial na explicação da consecução de emprego.

Um dos fatores é situacional-social, abarcando a estrutura do mercado laboral, com base em um contexto macroeconômico. Outros, situacional/pessoal e individual/objetivo dizem respeito a características bem delimitadas da pessoa em busca de emprego, que basicamente a identificariam, ao passo que os fatores pessoais e subjetivos referem-se a aspectos psicossociais, de caráter interno.

Essas variáveis entram no modelo de Blanch (1990), inseridas nas macrovariáveis contratabilidade e empregabilidade, que, juntas, constituem-se nos determinantes da ocupabilidade.

A ocupabilidade refere-se "ao grau de probabilidade de que um demandante de emprego obtenha uma ocupação laboral em uma dada conjuntura" (Blanch, 1990, p.184). Está diretamente relacionada aos fatores de contratabilidade $\mathrm{e}$ empregabilidade.

Por contratabilidade Blanch (1990) entende o ajuste entre as características do indivíduo em relação às características exigidas para determinada função, configurando-se na adequação entre os dois perfis dados. O primeiro perfil refere-se à consideração do papel exercido pelo mercado na inserção, em termos de estrutura e tendências do mercado laboral, ou seja, as possibilidades objetivas relativas à oferta de emprego. $\mathrm{O}$ segundo seria $\mathrm{o}$ concernente às características individuais objetivas. Essas abarcam os aspectos de escolaridade e formação/qualificação do sujeito, mas além dos níveis mais explícitos é preciso considerar aspectos biodemográficos, como sexo e idade, no sentido de seu possível papel socialmente discriminatório.

A empregabilidade, nas palavras de Blanch (1990),

é o grau de adequação do perfil psicossocial latente ao perfil típico de uma pessoa empregada, em um contexto dado. Representa um importante fator diferencial do currículo sócio-cultural oculto das pessoas em busca de emprego: esse complexo sistema de regras implícitas do jogo cotidiano, que se aprende tanto na escola, como na rua e na vida, feito de códigos e significados compartilhados, critérios valorativos, esquemas hermenêuticos, atitudes normalizadas, metas, estratégias e papéis comumente assumidos (Blanch, 1990, p. 182).

Partindo dessa definição de empregabilidade, o perfil psicossocial latente é composto de variáveis constituídas como mediadoras, tanto no processo de inserção laboral quanto na vivência do desemprego.

\section{MODELO DE EMPREGABILIDADE}

O modelo sistêmico de empregabilidade desenvolvido por Câmara (1999), com a colaboração do Grupo de Pesquisa em Psicologia Comunitária da PUCRS (GPPC), parte do Paradigma Ecológico, dos estudos anteriores do GPPC (Sarriera, 1998, 1999; Sarriera, Pizzinato, Rispoli, Trindade \& Lópes, 2000) e da análise de outros modelos de inserção ocupacional, ocupabilidade e empregabilidade (Montané, 1993; Blanch, 1990 \& Gazo, 1996): 


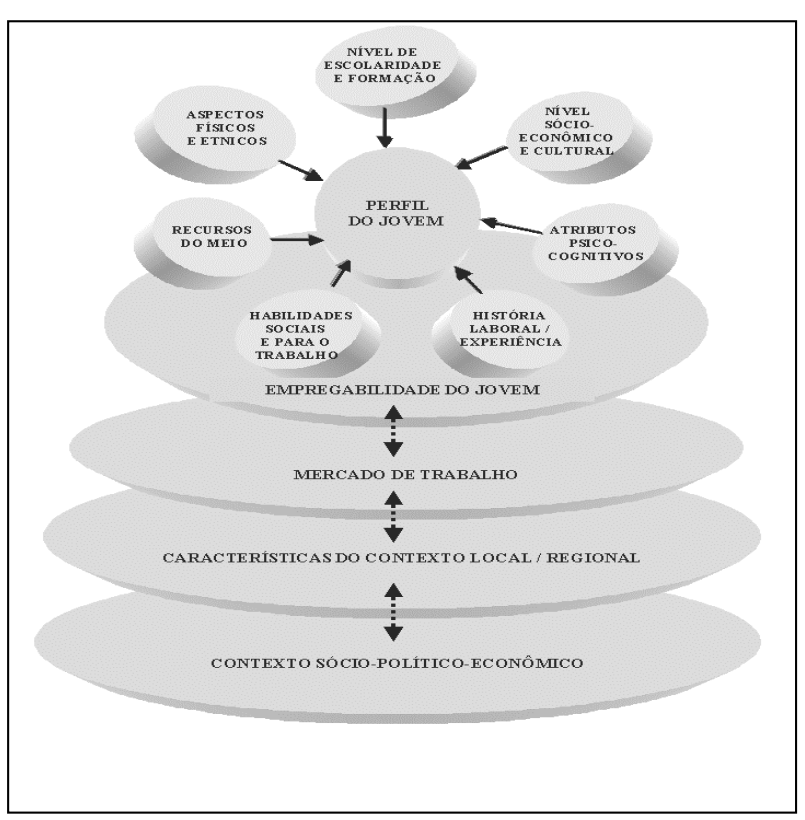

Figura 1. Modelo sistêmico de empregabilidade (Câmara \& Grupo de Pesquisa em Psicologia Comunitária).

O modelo apresentado na Figura 1 propõe a existência de três níveis de influência de caráter macrossistêmico: o contexto sócio-políticoeconômico, as características do contexto local/regional e o mercado de trabalho.

O contexto sócio-político-econômico determina as políticas de governo e as políticas sociais, em um país ou nas relações de âmbito maior, neste caso entre países. Esse contexto produz uma série de características relativas a um contexto local/regional. Este nível é intermediário e constitui-se das condições mais imediatas, referentes aos incentivos que a sociedade ou o governo oferecem, no que se refere ao mercado de trabalho. Ou seja, é um campo de incentivos e de políticas dirigidas. Assim, esse contexto, fortemente influenciado pelos contextos maiores, faz o elo de ligação para o outro nível considerado aqui: o jovem. No mercado de trabalho entram, portanto, além das características econômicas e políticas, os critérios específicos de cada setor econômico, os critérios de contratação nas empresas e as relações que se estabelecem entre selecionador e candidato, incluídas aí uma série de crenças e atribuições de ambas as partes, no momento da entrevista.

A partir dessa intersecção (Figura 1) e no que diz respeito ao perfil do jovem e aos diversos microssistemas com os quais se relaciona em sua história de vida e características pessoais como: aspectos físicos e étnicos, atributos psicocognitivos, nível de escolaridade e formação, nível sócioeconômico e cultural, história laboral/experiência, habilidades sociais para o trabalho e recursos do meio.
Os recursos do meio dizem respeito às oportunidades das quais os jovens dispõem, ou seja, as condições familiares e a qualidade das relações estabelecidas no sistema familiar, o acesso à escola e o tipo de ensino que obteve, a identificação com um grupo de amigos, mais ou menos saudável, e seu local de residência. Além disso, fazem parte os serviços (saúde, atividades de lazer) necessários para uma boa qualidade de vida, a renda familiar (se permite que o jovem siga estudando ou se exige que ele saia em busca de trabalho), entre outros. Dessa forma, os recursos do meio são responsáveis pelo tipo de vida que esse jovem leva, e, com isso, pela maneira que avalia a si mesmo e as próprias capacidades, bem como pela maneira como se defronta com a situação de busca de emprego.

Os atributos psicocognitivos são os responsáveis pela imagem que o jovem tem de si mesmo e da sociedade, sua auto-estima, seu estilo de afrontamento dos problemas e suas atitudes. Esses atributos, conforme Bronfenbrenner (1979/1996), são desenvolvidos no decorrer da vida e através das relações que esse jovem estabelece nos diferentes microssistemas.

Finalmente, faz parte do modelo de empregabilidade a história laboral e as experiências anteriores de trabalho. Aqui precisamos considerar que, em função da própria faixa etária, o jovem apresenta pouca ou nenhuma experiência laboral; além disso, normalmente pode apresentar experiências precárias de trabalho, como trabalhos temporários ou esporádicos. Assim, muitas vezes estas experiências podem até mesmo chegar a ter um peso negativo no momento da contratação.

A motivação que nos levou a realizar este estudo foi a carência de estudos na área de empregabilidade, bem como a necessidade premente de se implementarem formas de intervenção junto aos jovens, de maneira que possam desenvolver capacidades e recursos para se prepararem para as novas exigências do mercado de trabalho. Assim, nosso objetivo é verificar qual o perfil psicossocial de empregabilidade do jovem portoalegrense, a partir da concepção dos empregadores, através da identificação dos aspectos pessoais, formativos, de personalidade e psicossociais que são procurados pelo empregador nos jovens candidatos.

\section{MÉTODO}

\section{Amostra}

Foram pesquisadas 178 empresas das áreas da indústria, comércio e serviços, segundo uma 
distribuição proporcional das empresas em Porto Alegre. Responderam ao questionário os responsáveis pela seleção de jovens das empresas selecionadas, as quais foram retiradas de uma listagem fornecida pelo SINE/Adolescente, devendo apresentar contrato de trabalho com jovens e não apenas vínculos de estágio. A seguir, foram realizados contatos por telefone e marcadas as entrevistas, que se realizaram no ambiente das empresas, com os responsáveis pela seleção de pessoal.

Tabela 1. Características da amostra. Distribuição por médias e freqüências.

\begin{tabular}{llcc}
\hline \multicolumn{1}{c}{ EMPRESAS } & & \\
\hline & & f & \% \\
\hline \multirow{2}{*}{ Setores } & Comércio & 63 & 35 \\
& Indústria & 23 & 13 \\
& Serviços & 92 & 52 \\
\hline Programa de & Possui ou está implantando & 102 & 57 \\
Qualidade Total & Não possui & 76 & 43 \\
\hline \multirow{2}{*}{ Porte (critério de } & Microempresa (1-19f.) & 77 & 44 \\
número de & Mequeno porte (20-99f.) & 61 & 34 \\
funcionários) & Grandio porte (100-499f.) & 29 & 16 \\
& \multicolumn{1}{c}{ SELECIO (500 ou mais f.) } & 11 & 6 \\
\hline \multirow{2}{*}{ Cargo } & Chefias de RH & & \\
& Chefias de RH com formação em Psicologia & 74 & 41 \\
& Proprietário ou sócio & 35 & 20 \\
& Outros cargos & 57 & 32 \\
\hline \multirow{2}{*}{ Formação } & Em Psicologia ou Administração & 32 & 18 \\
& Outras formações & 117 & 66 \\
& Não respondeu & 29 & 16 \\
\hline Sexo & Homens & 86 & 48 \\
& Mulheres & 92 & 52 \\
\hline
\end{tabular}

\section{Instrumento}

Para esta pesquisa foi elaborado um instrumento específico, através de duas etapas: 1) entrevistas com 6 sujeitos (selecionadores) pertencentes a empresas com características similares às empresas que foram escolhidas para o estudo definitivo. Realizou-se uma análise qualitativa, de tipo categorial, acerca do conteúdo das entrevistas, a qual serviu como subsídio para a construção do instrumento; 2) elaboração do instrumento de pesquisa (questionário), composto por 25 questões fechadas, abarcando critérios biodemográficos, pessoais, de habilidades sociais, de escolaridade e institucionais.

Para a análise dos dados do instrumento definitivo utilizamos uma análise descritiva, a partir de medidas de tendência central e de dispersão, a fim de mapear os aspectos configurativos do perfil de jovens esperado pelo empregador.

\section{RESULTADOS}

Os resultados encontrados em nosso estudo representam uma série de elementos que poderão configurar um mapa de aspectos envolvidos na questão da empregabilidade de jovens em Porto Alegre, como verificamos a seguir.

\section{Critérios biodemográficos, pessoais e habilidades sociais na contratação de jovens:}

A questão referente à preferência por um determinado "sexo" na contratação, num primeiro momento, não apresentou dados discriminativos.

Quanto ao "estado civil" do candidato, a maioria $(74,7 \%)$ é indiferente; entretanto, um percentual $(23,6 \%)$ indica uma preferência por jovens solteiros. Os respondentes justificam esta preferência através de aspectos como maior disponibilidade de tempo do funcionário, maior responsabilidade, compatibilidade do salário com o sustento familiar, dedicação e eficiência.

É importante considerar que os jovens da faixa etária de 14 a 21 anos que estavam estudando contam com pouca ou nenhuma "experiência de trabalho", e muitos estão em busca de seu primeiro emprego. Entretanto, na visão do empregador, ter experiência aparece como um critério muito importante para a contratação.

Tabela 2. Aspectos relevantes da experiência de trabalho do jovem. Distribuição de freqüências e porcentagens.

\begin{tabular}{lccccccc}
\hline \multirow{2}{*}{$\begin{array}{l}\text { Aspectos relevantes da } \\
\text { experiência de trabalho }\end{array}$} & \multicolumn{2}{c}{ Sim } & \multicolumn{3}{c}{ Não } & \multicolumn{3}{c}{ Não responde } & Total \\
\cline { 2 - 8 } & $\boldsymbol{f}$ & $\mathbf{\%}$ & $\boldsymbol{f}$ & $\mathbf{\%}$ & $\boldsymbol{f}$ & $\boldsymbol{\%}$ & $\boldsymbol{f}$ \\
\hline Experiência na função & 89 & $\mathbf{5 0 , 0}$ & 79 & 44,4 & 10 & 5,6 & 178 \\
Experiência geral de trabalho & 115 & $\mathbf{6 4 , 6}$ & 51 & 28,7 & 12 & 6,7 & 178 \\
Preferível não ter experiência & 48 & 27,0 & $\mathbf{1 1 3}$ & 70,2 & 17 & 9,6 & 178
\end{tabular}

Com relação aos "motivos de saída do último emprego", fica claro que, de alguma forma, são levantadas referências sobre o candidato. Quanto a esse aspecto, encontramos a preocupação do empregador com possíveis problemas de comportamento do funcionário, bem como problemas relacionados a autoridade, além do absenteísmo.

Tabela 3. Importância atribuída ao motivo de saída do último emprego. Distribuição de médias e desvio padrão.

\begin{tabular}{lcc}
\hline Motivo de saída do último emprego & $\boldsymbol{m}^{*}$ & $\boldsymbol{D p}$ \\
\hline Mudança de residência & 1,91 & 1,08 \\
Mudança no horário escolar & 2,35 & 1,23 \\
Absenteísmo & $\mathbf{3 , 8 0}$ & 1,43 \\
Problemas com a chefia & $\mathbf{3 , 9 0}$ & 1,33 \\
Insatisfação com o salário & 3,37 & 1,13 \\
Aspectos de comportamento & $\mathbf{4 , 2 0}$ & 1,27 \\
\hline
\end{tabular}

Nota:* 1. Nenhuma; 2. Pouca; 3. Regular; 4. Bastante; 5. Muita

Os critérios referentes a "higiene e limpeza" (primeiro contato do selecionador com o jovem), têm 
preponderância, ou seja, causam maior impacto do que os aspectos de desenvoltura social, que se apresentam num segundo momento. No que se refere a "cuidado com odores de transpiração e mau-hálito" , verifica-se bastante homogeneidade entre os respondentes quanto à importância conferida a este aspecto.

O mais desejável é o bom comportamento, a estabilidade emocional, a identificação com a empresa e a agilidade, fatores que revelam uma maior importância conferida à adequação do jovem às regras da empresa do que iniciativa pessoal, extroversão e mesmo autonomia, que não são vistos como desejáveis. Ressaltamos que o item "bom comportamento" apresenta a maior média entre os demais, e sua dispersão é a menor. Estes dados nos levam a verificar a grande importância que é conferida a aspectos voltados à disciplina e à adequação do jovem. Ao contrário, a "introversão" é um aspecto definitivamente indesejável no consenso dos respondentes, e "saber lidar com dinheiro" também não parece ser uma necessidade no olhar do empregador.

Ressaltamos também a importância conferida à estabilidade emocional, acompanhada de agilidade e identificação com a empresa, como observamos na Tabela 4.

Tabela 4. Qualidades pessoais procuradas pelo selecionador no jovem. Distribuição de médias e desvio padrão.

\begin{tabular}{lll}
\hline Qualidades & $\boldsymbol{m}^{*}$ & $\boldsymbol{D p}$ \\
\hline Desenvoltura & 1,50 & 0,52 \\
Amabilidade & 1,28 & 0,54 \\
Estabilidade emocional & $\mathbf{1 , 6 3} \uparrow$ & $\mathbf{0 , 4 8}$ \\
Calma & 1,45 & 0,57 \\
Bom comportamento & $\mathbf{1 , 8 4} \uparrow$ & $\mathbf{0 , 3 6}$ \\
Agilidade & $\mathbf{1 , 6 1} \uparrow$ & 0,52 \\
Habilidades para comunicação & 1,45 & 0,56 \\
Saber lidar com dinheiro & $\mathbf{0 , 9 4} \downarrow$ & 0,68 \\
Autonomia & 1,28 & 0,54 \\
Identificação com a empresa & $\mathbf{1 , 6 1} \uparrow$ & 0,52 \\
Extroversão & 1,14 & 0,69 \\
Introversão & $\mathbf{0 , 2 9} \downarrow$ & 0,50 \\
Maturidade & 1,50 & 0,55 \\
\hline
\end{tabular}

Nota:* 0. Irrelevante; 1. Desejável; 2. Imprescindível

\section{Critérios relacionados à escolaridade}

No que diz respeito à escolaridade exigida, em média verificamos que as repostas concentram-se entre ensino médio incompleto, ou em andamento, e ensino médio completo. Ou seja, quase metade das empresas entrevistadas já não contratam mais jovens com apenas ensino fundamental, ao passo que cresce uma demanda por jovens que estejam realizando cursos universitários.

Tabela 5. Nível de escolaridade exigido para a contratação de jovens. Distribuição de freqüências e porcentagens.

\begin{tabular}{llcc}
\hline \multicolumn{2}{l}{ Nível de escolaridade } & $f$ & $\mathbf{\%}$ \\
\hline 1. & Não precisa ter escolaridade mínima & 7 & 3,9 \\
2. & De 3 a 5 série do ensino fundamental & 6 & 3,4 \\
3. De 6 a 8 série do ensino fundamental & 15 & 8,4 \\
4. & Ensino fundamental completo & 26 & 14,6 \\
5. & Ensino médio incompleto ou em andamento & $\mathbf{4 0}$ & $\mathbf{2 2 , 5}$ \\
6. & Ensino médio completo & $\mathbf{4 7}$ & $\mathbf{2 6 , 4}$ \\
7. & Ensino médio técnico & 11 & 6,2 \\
8. & Cursado 3 ensino superior & 26 & 14,6 \\
\hline
\end{tabular}

Nota: $\mathrm{m}=5,25, \mathrm{dp}=1,78$

Em relação a ter cursado "cursos profissionalizantes" ou não, em média os empregadores consideram de "regular" a "bastante importante" o fato de o jovem tê-los realizado. Dentre os cursos preferidos, ressalta-se a importância da informática, enquanto cursos técnicos tecnológicos e cursos técnicos da área de humanas apresentam uma distribuição eqüitativa.

\section{Critérios institucionais}

A seleção de pessoas em uma empresa consiste muito mais nas necessidades da própria empresa do que nas necessidades do trabalhador. Sobre isso, não podemos deixar de referir os critérios que precisam ser satisfeitos para a realidade daquela empresa e as escolhas que ali se realizam. O principal objetivo é o de se ter o melhor aproveitamento com o menor custo possível.

Quanto ao processo de seleção nas empresas, encontramos a importância conferida à entrevista, seja com a chefia direta seja com o responsável por Recursos Humanos. Além disso, a análise documental é realizada através de fichas ou currículos, deixando a um segundo plano a análise da carteira de trabalho. Estes resultados revelam que o empregador está consciente de que a carteira de trabalho do jovem pouco ou nada diz de suas capacidades, uma vez que esta clientela tem pouca ou nenhuma experiência de trabalho anterior. Nesse sentido, ao se tratar de jovens, são avaliados aspectos mais relacionados à formação, os quais se revelam nas fichas ou nos currículos.

Um dos aspectos fundamentais para a contratação é a percepção dos selecionadores acerca do interesse que o candidato tem naquele emprego. Quanto a isso, referem que a melhor maneira de identificar esse interesse é pela clareza do candidato quanto às suas metas (se empregado), no contexto específico daquela empresa, muito mais do que querer fazer carreira, de forma genérica, ou mesmo demonstrar necessidade de 
trabalhar. Ou seja, o que importa é um certo nível de direcionamento de objetivos e estratégias para o alcance destes.

Tabela 6. Como é realizada a avaliação do interesse do candidato pelo emprego. Distribuição de freqüências e porcentagens.

\begin{tabular}{lccccccc}
\hline Interesse do candidato & \multicolumn{2}{c}{ Sim } & \multicolumn{2}{c}{ Não } & \multicolumn{2}{c}{ Não responde } & Total \\
pelo emprego & $\boldsymbol{f}$ & $\boldsymbol{\%}$ & $\boldsymbol{f}$ & $\boldsymbol{\%}$ & $\boldsymbol{f}$ & $\boldsymbol{\%}$ & $\boldsymbol{f}$ \\
\hline Pela manifestação de necessidade & 112 & 62,9 & 63 & 35,4 & 3 & 1,7 & 178 \\
Pelo interesse em fazer carreira & 113 & 63,5 & 61 & 34,3 & 4 & 2,2 & 178 \\
Pela clareza de metas apresentada & 157 & $\mathbf{8 8 , 2}$ & 21 & 11,8 & 0 & 0 & 178
\end{tabular}

Com relação à importância atribuída a aspectos normativos presentes na contratação de jovens, pedimos aos respondentes que ordenassem alguns aspectos de acordo com a importância a eles atribuída, indo de 5 - mais importante a 1 - menos importante. Verificamos que os empregadores preocupam-se primeiramente com as questões legais envolvidas no processo de contratação; em segundo lugar, com a segurança no trabalho; e em terceiro com oportunizar que o jovem continue estudando. Sem dúvida, estes aspectos relacionam-se a possíveis problemas que o empregador possa encontrar ao contratar jovens, principalmente os menores de 18 anos. Quanto à segurança no trabalho, sabemos que algumas características típicas da adolescência tornam o jovem, muitas vezes, mais arredio à utilização de equipamentos de segurança.

Tabela 7. Importância atribuída pelo selecionador a aspectos normativos. Distribuição de médias e desvio padrão e ordem de importância.

\begin{tabular}{lccc}
\hline $\begin{array}{l}\text { Importância atribuída a } \\
\text { aspectos normativos }\end{array}$ & $\boldsymbol{m}^{*}$ & $\boldsymbol{d} \boldsymbol{p}$ & $\begin{array}{c}\text { Ordem de } \\
\text { importância }\end{array}$ \\
\hline Questões legais & 3,85 & 1,31 & $1^{\circ}$ \\
Segurança no trabalho & 3,25 & 1,13 & $2^{\circ}$ \\
Oportunizar a continuidade de estudos & 3,17 & 1,52 & $3^{\circ}$ \\
Insalubridade da tarefa & 2,40 & 1,27 & $4^{\circ}$ \\
Especificidade de encargos sociais & 2,32 & 1,20 & $5^{\circ}$ \\
\hline
\end{tabular}

Estes foram os resultados encontrados, em nossa amostra, no que se refere às características de contratação de jovens nas empresas de Porto Alegre.

\section{ANÁLISE E DISCUSSÃo DOS RESULTADOS}

\section{Perfil de empregabilidade}

Os resultados passam um perfil que podemos considerar bastante delimitado acerca do jovem "empregável": pode ser homem ou mulher, dependendo da função. Às mulheres cabem os serviços mais delicados, e aos homens, os mais pesados. Deve ser solteiro, ter estudado no mínimo até o ensino médio, tendo apresentado um bom desempenho em termos de adequação de comportamento. O melhor é que já conte com alguma experiência prévia de trabalho, em que deve não ter tido problemas de comportamento com colegas ou com superiores. Emocionalmente é importante que seja uma pessoa madura e com metas e projetos vitais bem definidos. Deve saber comportar-se em situação de entrevista e ganhar a empatia do selecionador. Deve ser quase perfeito.

Como características de personalidade, encontramos a importância conferida ao bom comportamento e, juntamente a isso, a identificação com a empresa. Entretanto, é importante que o jovem tenha uma certa estabilidade emocional e demonstre agilidade para trabalhar. O bom comportamento e a disciplina são os aspectos com maior índice de respostas dos selecionadores. Podemos pensar, baseados nos pressupostos de Montané (1993), na importância das atitudes de inserção do indivíduo, o que se manifesta através de seu comportamento frente à busca de emprego. Entretanto, esses aspectos teriam raízes mais profundas, revelando, além do caráter comportamental e mesmo de treinamento, os componentes afetivos e psicocognitivos, instâncias mais profundas na personalidade do jovem.

Quem é este candidato perfeito? É o solteiro ou aquele que precisa sustentar uma família? É aquele que teve um bom desempenho na escola ou aquele que soube comportar-se? É aquele que chegou ao fim de sua formação escolar básica ou aquele que não pôde concluí-la porque estava tendo suas primeiras experiências precoces de trabalho? Em que escola ele estudou? Ele tinha carteira assinada em seus primeiros empregos ou submeteu-se a condições de exploração? Onde vive? Onde viveu? Ele, misteriosamente, mesmo sendo adolescente, é uma pessoa madura?

Isto não está escrito. Estas respostas nunca são dadas de forma espontânea e direta. Talvez, nem mesmo o empregador saiba ou queira saber as contingências que determinam um perfil perfeito. Ninguém fala do perfil perfeito, mas ele existe e se reproduz num modelo bastante diferente do sistêmico.

\section{Modelo empírico de empregabilidade}

Todos esses aspectos, que configuram o perfil de empregabilidade do jovem portoalegrense, fazem-nos rever a adequação do modelo sistêmico de empregabilidade, proposto inicialmente, a partir da análise de nossa realidade.

A princípio, no modelo que propusemos hipotetizamos que existia uma relação multicausal entre os diversos componentes envolvidos na 
empregabilidade de jovens. Nesse sentido, em certa medida um fator determinaria, e seria simultaneamente determinado pelo outro, sendo essa relação verdadeira no micro, no meso e mo macrossistema, bem como nas interações entre eles.

Porém, com base nos resultados encontrados entre a amostra de empresas de Porto Alegre, podemos observar que a relação que se estabelece entre os fatores, na empregabilidade, não têm uma configuração essencialmente sistêmica, no entendimento dos empregadores, mas possivelmente linear, como apresentamos no esquema a seguir:

\begin{tabular}{|c|c|c|c|c|}
\hline \multirow{3}{*}{ CONTEXTO } & \multicolumn{2}{|l|}{$\begin{array}{l}\text { NÍVEL SÓCIO- } \\
\text { ECOÔMICOE } \\
\text { CULTURAL }\end{array}$} & $\begin{array}{l}\text { H A B ILID A DES } \\
\text { SOCIA IS }\end{array}$ & $\underset{\text { INSERÇ ÃO }}{7}$ \\
\hline & $\mid L$ & $\begin{array}{l}\text { NÍVEL DE } \\
\text { ESCOLARIDADE }\end{array}$ & $\begin{array}{l}\text { ATRIBUTOS } \\
\text { PSICOCOGNITIV OS }\end{array}$ & LAB ORAL \\
\hline & & $\begin{array}{l}\text { ASPECTOS } \\
\text { FÍSICOS } \\
\text { RECURSOS } \\
\text { DO MEIO }\end{array}$ & $\begin{array}{l}\text { HISTÓRIA } \\
\text { LABORAL/ } \\
\text { EXPERIÊNCIA } \\
\end{array}$ & \\
\hline
\end{tabular}

Figura 2. Modelo de empregabilidade construído a partir dos resultados da pesquisa

Segundo o novo modelo, advindo dos nossos resultados, o nível sócio-econômico-cultural do jovem em busca de emprego determina a inserção laboral. $\mathrm{Ou}$ seja, de acordo com seu nível econômico e cultural verifica-se uma maior ou menor permanência na escola, o que configura o nível de escolaridade que o jovem possui. Assim mesmo, as exigências das empresas com relação ao aspecto físico e vestimenta estão muito relacionados com o nível socioeconômico do jovem e com os recursos quanto a redes de apoio do meio onde vive esse jovem, no sentido de amigos ou de conhecidos que possam, de alguma forma, auxiliar no processo de inserção, seja nos recursos de saúde com que conta, seja em outros.

Ainda, o nível sócio-econômico e cultural de onde procede o jovem se reflete nas habilidades sociais que apresenta e que foram sendo aprendidas durante $o$ decorrer de sua infância e adolescência. É o processo de socialização, que se dá principalmente na família, na comunidade e na escola, sendo determinantes do repertório do jovem em termos de habilidades sociais.

Além de ter repercussões sobre habilidades socialmente aprendidas, o nível de escolaridade é também um dos responsáveis pelos atributos psicocognitivos da personalidade do jovem. Como esses atributos, de caráter interno, são desenvolvidos nos ambientes onde o indivíduo se educa e onde se estabelecem as representações que ele tem de si mesmo, no sentido de sua auto-estima, seu estilo de afrontamento e suas atitudes, podemos pensar na importância da escola e da família como microssistemas que propiciam o dimensionamento desses aspectos, à medida que a criança ou o jovem se inserem em um contexto formal que facilita o processo de auto-avaliação, principalmente no que diz respeito a suas competências (Kimmel \& Weiner, 1998).

Um outro aspecto, que está definido pelos recursos e pelas oportunidades do meio e que é influenciado indiretamente pelo nível socioeconômico e cultural do jovem, é sua história laboral, incluindo experiências prévias de emprego.

Conforme o Quadro 2, os fatores que apresentam uma influência direta sobre a inserção laboral de jovens em nossa realidade seriam a experiência prévia de trabalho e a história laboral, as habilidades sociais para o trabalho e os atributos psicocognitivos, aspectos que configuram os níveis experiencial, comportamental e cognitivo do jovem. Entretanto, para que se constituam esses aspectos são fundamentais a aparência (aspecto) física, o nível de escolaridade e os recursos do meio em que se insere esse jovem (contexto vital). Por fim, o grande determinante desses três fatores intermediários seria, em última instância, o nível socioeconômico e cultural do jovem, que somente pode ser avaliado a partir da caracterização em um determinado contexto, mais amplo.

Passamos a essa configuração do perfil de empregabilidade do jovem em função de termos observado, em nossos resultados, que muitos dos critérios valorizados pelo selecionador referem-se a características, apresentadas pelo jovem, decorrentes de um desenvolvimento vital satisfatório, para o qual contam, fundamentalmente, as experiências mais favoráveis, seja na escola seja no próprio mercado de trabalho. Nesse sentido, não é possível separar esses critérios do nível socioeconômico e cultural do jovem.

Dessa forma, verificamos que existe um fator social e econômico muito forte, que determina as possibilidades de inserção de jovens. Embora os entrevistados não tenham trazido dados diretamente relacionados a uma discriminação social em termos econômicos, fica claro que são esses aspectos que fornecem ao candidato maiores ou menores possibilidades de inserção, revelando a linearidade dos fatores associados.

\section{CONSIDERAÇÕES FINAIS}

Este estudo direciona-se a aspectos bastante práticos da seleção de jovens, baseado em que consideramos que o perfil de empregabilidade esperado pelo empregador é um perfil ideal, que se distancia da realidade social dos jovens. Além disso, o perfil encontrado não parece estar direcionado 
unicamente para jovens, tendo em vista que o empregador busca uma maturidade e uma disponibilidade para o trabalho que não condizem com a etapa da adolescência.

É fundamental, a partir deste quadro, que sejam desenvolvidos programas que instrumentalizem os jovens para o processo de inserção no mercado de trabalho, visando, com isso, minimizar as dificuldades de caráter social e etário que eles encontram neste percurso. Programas como este vêm sendo desenvolvidos e implementados pelo Grupo de Pesquisa em Psicologia Comunitária da PUCRS, com resultados bastante satisfatórios no que diz respeito a uma definição pessoal dos jovens, desenvolvimento de habilidades sociais para o trabalho e conhecimento da legislação trabalhista. Encontramos, porém, dificuldades em reverter, na realidade destes jovens, defasagens em termos de escolaridade, e mesmo aspectos psicocognitivos que estão de certa forma consolidados e adquirem, muitas vezes, um caráter de submissão frente à possível exploração do trabalho de jovens.

Mas, mais do que isso, é fundamental que voltemos nossa atenção para intervenções direcionadas às empresas, no sentido da realização de um trabalho que traga à tona a conscientização social, no que tange ao problema do desemprego juvenil. É preciso investir em jovens, é preciso investir no que temos hoje, na condição de uma possibilidade, para que possamos, no futuro, ter profissionais competentes e comprometidos com o desenvolvimento econômico e social de nosso pais. Consideramos, dessa forma, como prementes trabalhos que sejam desenvolvidos no cerne das empresas e no âmbito empresarial, de forma mais ampla, colocando em pauta a discussão do papel do empresariado e dos empregadores no crescimento de pessoas, participando do compromisso social de responsabilizar-se pelo desenvolvimento de nossos jovens, tanto profissionalmente como enquanto pessoas em processo de aprendizagem.

\section{REFERÊNCIAS BIBLIOGRÁFICAS}

Aguiar, M. A. S. (1983). Desemprego: flagelo e desperdício da força de trabalho. Rio de Janeiro: IBASE/CODECRI. Blanch, J. M. (1990). Del viejo al nuevo paro. Barcelona: PPU.
Bronfenbrenner, U. (1996). A ecologia do desenvolvimento humano: experimentos naturais e planejados. Porto Alegre: Artes Médicas. (Originalmente publicado em 1979).

Câmara, S. G. (1999). Empregabilidade do jovem portoalegrense: Um levantamento do perfil psicossocial esperado pelas empresas das áreas da indústria, comércio e serviços. Dissertação de Mestrado. Pontifícia Universidade Católica do Rio Grande do Sul. Porto Alegre.

Gazo, P. F. (1996). La inserción del universitario em el mercado de trabajo. Barcelona: EUB.

Kimmel, D. \& Weiner, I. (1998). La adolescencia: una transición del desarrollo. Barcelona: Ariel Psicología.

Montané, J. (1993). Orientación ocupacional. Barcelona: CEAC.

Sarriera, J. C., Chies, A., Falck, D., Giacomolli, A. \& Silva, A. (1994). A escolha profissional e o processo de inserção sócio-laboral: dificuldades e alternativas. Psico. 25 (1), 157-165.

Sarriera, J. C. \& Verdin, R. (1996). Os jovens à procura de trabalho: uma análise qualitativa. Psico. 27 (1), 59-70.

Sarriera, J. C. \& Teixeira, R. P. (1997). Itinerários descritivos e diferenciais de transição da escola ao trabalho dos jovens de Porto Alegre. Psico. 28 (2), 117137.

Sarriera, J. C. (1998). Da orientação profissional para a inserção de jovens no trabalho. ABOP. 22, 75-80.

Sarriera, J. C. (1999). Uma perspectiva de orientação profissional para o próximo milênio. ABOP. 3 (1), 85-96.

Sarriera, J. C.; Pizzinato, A.; Rispoli, A.; Trindade, T. \& López, V. (2000). Adolescentes de classes populares à procura de trabalho: suas dificuldades e expectativas. Psicologia Argumento. 18 (26), 85-104.

Westergaard, C. K. \& Kelly, J. G. (1992). Una epistemologia contextualista para la investigación ecológica. Em J. G. Kelly, E. Saforcada, C. K. Westergaard, D. Altman, R. Kahn, D. Stokols \& H. Rausch (Orgs.). Psicología Comunitária: el enfoque ecológico-contextualista. (pp. 35-51). Buenos Aires: Centro Editor de América Latina. 